\title{
Unsteady Heat Transfer and Direct Comparison to Steady-State Measurements in a Rotor-Wake Experiment
}

J.E. O'Brien, and R.J. Simoneau

Lewis Research Center

Cleveland, Ohio

and

J.E. LaGraff

Syracuse University

Syracuse, New York

and

K.A. Morehouse

Lewis Research Center

Cleveland, Ohio 


\title{
UNSTEADY HEAT TRANSFER AND DIRECT COMPARISON TO STEADY-STATE
}

\author{
MEASUREMENTS IN A ROTOR-WAKE EXPERIMENT* \\ J.E. O'Brien and R.J. Simoneau \\ National Aeronautics and Space Administration \\ Lewis Research Center \\ Cleveland, ohio 44135 \\ J.E. LaGraff \\ Syracuse University \\ Mechanical and Aerospace Engineering Department \\ Syracuse, N.Y. 13210 \\ K.A. Morehouse \\ National Aeronautics and Space Administration \\ Lewis Research Center \\ Cleveland, Ohio 44135
}

\section{SUMMARY}

An experimental effort has been carried out in which circumferentially local and time-resolved heat transfer measurements have been obtained for a circular cylinder in crossflow located downstream of a rotating spoked wheel wake generator in a steady flow tunnel. The unsteady heat transfer effects were obtained by developing an extension of a thin film gauge technique employed to date exclusively in short-duration facilities. A direct comparison has been made between the time-average thin $f i l m$ results and conventional steady-state heat transfer measurements, yielding excellent agreement. Timeaveraged wake-induced stagnation heat transfer enhancement levels above the no-wake case (one percent freestream turbulence) were found to be about 10 percent for the four cylinder Reynolds numbers (ranging from 36000 to 96000 ) included in the study. This enhancement level was nearly independent of bar passing frequency and was related directly to the time integral of the heat transfer spikes observed at the bar passing frequency. These wake-induced heat transfer spikes were observed to have peak magnitudes averaging 30 to 40 percent above the inter-wake heat transfer level.

\section{INTRODUCTION}

As a result of several recent studies (e.g. refs. 1 to 3 ), the nature and significance of wake-related flow unsteadiness in turbomachinery blading and its profound effect on heat transfer are beginning to emerge: This type of research represents the next logical step toward a more complete and realistic understanding of the complex flow fields associated with turbomachines.

Unsteady heat transfer has been measured in several short-duration facilities by means of platinum thin film heat flux gauges, providing detailed time-

*A shortened version of this report was presented at the 8 th International Heat Transfer Conference, San Francisco, California, August 17-22, 1986. 
resolved heat flux data from airfoils located either in a cascade (in which the wakes shed by a nozzle guide vane row were simulated by means of a rotating spoked wheel) (refs. 1 and 2) or in an actual turbine stage (ref. 3). The usage of this type of instrumentation enables the researchers to take full advantage of the heated gas flow produced by these short-duration facilities. It is impossible, however, to directly measure steady-state heat transfer by more conventional techniques in these facilities because of the time scales associated with their operation. The goal of the present study was to establish a means for utilizing the thin film gauge technique for measuring average and time-resolved heat transfer in a steady-flow tunnel and to provide a direct comparison between conventional steady-state heat transfer measurements and the thin-film gauge technique in a rotor-wake experiment. In addition, this study provided useful information on the effect of simulated rotor wakes on heat transfer (average and time-resolved) to the stagnation region of a circular cylinder in crossflow. This information can in turn be related to turbomachinery stagnation region heat transfer, since turbine airfoil leading edges are normally circular in profile.

This paper is the third in a series focused on identifying the effects of simulated rotor wakes on heat transfer from a downstream circular cylinder. The first paper (ref. 4) reported the effects of the wakes on overall average heat transfer, and the second (ref. 5) identified the circumferentially local effects on average heat transfer. Future work will concentrate on local and time-resolved effects on both circular cylinders and actual airfoils in an annular cascade.

Dr. Michael G. Dunn assisted in the fabrication of the thin-filminstrumented cylinder.

NOMENCLATURE

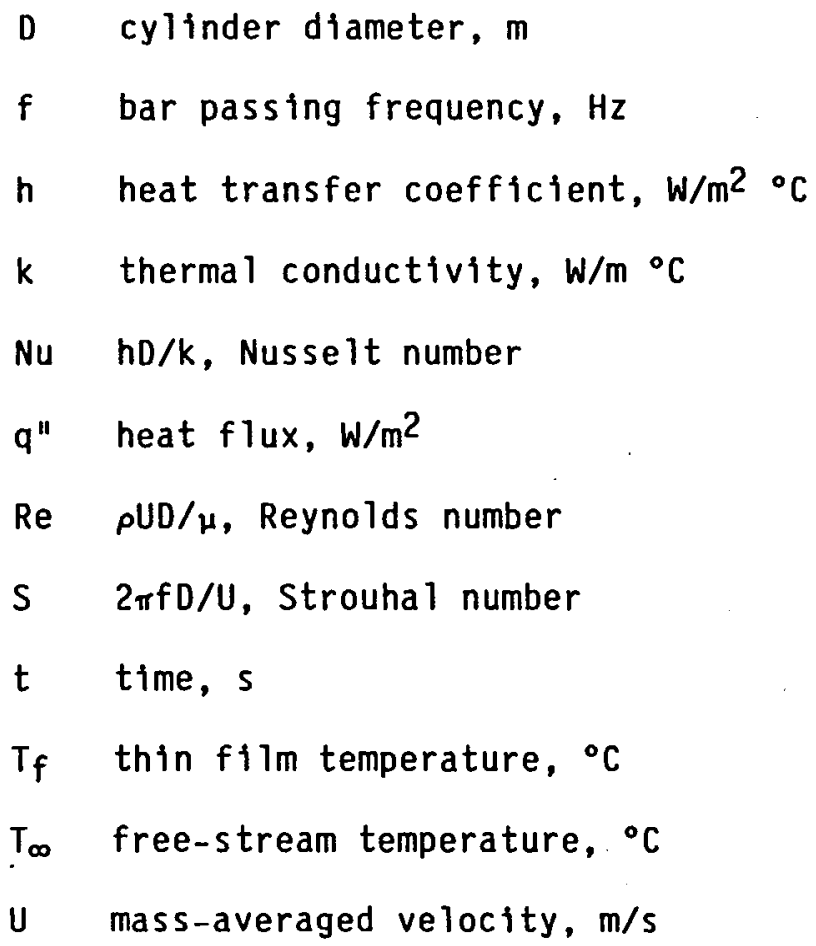




$$
\begin{aligned}
& \rho \quad \text { air density, } \mathrm{kg} / \mathrm{m}^{3} \\
& \mu \quad \text { air viscosity, Ns/m }
\end{aligned}
$$

\section{THE EXPERIMENTS}

The unsteady flow simulation technique utilized in the experiments is diagrammed schematically in figure 1. A rotating spoked wheel located in the main flow passage acts as a disturbance (or wake) generator. The wakes produced by moving the series of circular cylindrical bars (the spokes) in front of the downstream test object have been shown to closely duplicate the correct relative velocity vector diagram of a turbomachinery rotor unsteady flow (refs. 5 and 6 ). The focus of the experiments was to determine the effect of the wake passage on the time-resolved heat transfer in the stagnation region of a stationary downstream circular cylinder.

The experiments were carried out in the annular flow wind tunnel shown in figure 2. Ambient air was drawn from the laboratory room through a flowconditioning section and into the test section annulus via an 8.3 to 1 contraction. The test-section annulus $(40.64 \mathrm{~cm} 0 . d ., 27.05 \mathrm{~cm} \mathrm{i.d.)}$ contained a turbulence grid (10 mesh woven wire) which produced a free-stream turbulence intensity of about 1.2 percent measured in the stator plane, $21.0 \mathrm{~cm}$ downstream of the grid.

The wake-generating rotor was fitted with 24 equaliy spaced spokes, 3.18 $\mathrm{mm}$ in diameter. The rotor was driven externally using a controlled variablespeed dc motor at speeds which were selected in a range from 500 to $3700 \mathrm{rpm}$. The spacing between the rotor and stator was fixed at $25.4 \mathrm{~mm}$, a distance of two stator pin diameters. Each of the eight stator pins was backed by a splitter plate to eliminate oscillations associated with alternate vortex shedding.

Downstream of the stator row, the air encounters a set of flow straighteners designed to minimize the effects of swirl. After negotiating the $90^{\circ}$ bend at the bottom of the rig, the flow passes through an ASME standard sharp-edged orifice and is then exhausted through a throttleable butterfly valve into the laboratory exhaust system.

Flow velocities in the test section could be set from 10 to $120 \mathrm{~m} / \mathrm{s}$, yielding Reynolds numbers based on stator pin diameter up to 96000 . The bar passing frequency, $f$, was a function of rotor speed and ranged from 200 to $1480 \mathrm{~Hz}$. It was nondimensionalized in terms of the strouhal number, $S$, defined $s$

$$
S=\frac{2 \pi f D}{U}
$$

where $D$ is the stator diameter and $U$ is the mass-averaged velocity. The Strouhal number range covered in the experiments was from 0.15 to 1.25 . Typical aircraft turbines operate with leading-edge-diameter Strouhal number near 1.0 .

The heat transfer data discussed herein were obtained from the three separate instrumented stator pins shown in figure 3 . The first of these, shown in figure 3(a), was developed for a separate investigation carried out in the 
same rig. This $25.4 \mathrm{~mm}$ o.d. cylinder, which is described in detail in reference 5 , was built up of individually heated and temperature-controlled copper strips for determining steady-state local heat transfer. All of the strips and adjacent guard heaters were maintained at essentially the same temperature, minimizing conduction losses and presenting a uniform wall-temperature boundary condition to the flow.

The two remaining $12.7 \mathrm{~mm} 0 . d$. instrumented stator pins shown in figure 3 were developed specifically for this study. The stator pin shown in figure 3 (b) was fabricated out of machinable ceramic rod. Seven platinum thin film gauges (approximately $100 \AA$ thick, $0.25 \mathrm{~mm}$ wide, and $2.8 \mathrm{~mm}$ long) were deposited on the surface of the ceramic rod at $20^{\circ}$ circumferential spacings. The thin films were operated in the constant-current (approximately $8 \mathrm{~mA}$ ) mode and as such acted as sensitive, high-response (response time approximately 10-8 sec) surface temperature sensors. As mentioned previousiy, these types of thin film gauges, originally developed by vidal (ref. 7 ), have been employed extensively for the direct measurement of surface heat flux in several shortduration facilities (refs. 1 to 3 and 7 ). Details of thin-film gauge measurement and analysis techniques are available from references 8 to 11 . The technique involves processing the time-varying voltage drop across the thin films by means of either analog circuitry (refs. 11 and 12) or high-speed digital data acquisition and subsequent numerical analysis (ref. 3 ). Both data reduction strategies adopt the assumption that the thin-film gauge and its substrate undergo one-dimensional unsteady conduction in a semi-infinite medium for the time period during which measurements are obtained.

In the short-duration facilities, the instrumented test object is essentially at ambient temperature prior to a test run. Heat transfer occurs after firing of the tunnel whereupon the test object is subjected to an elevatedtemperature, high-velocity flow for a short time period (typically $15 \mathrm{~ms}$ ).

In order to utilize this thin-film technique in a steady-flow tunnel, the test cylinder of the present experiments was uniformly preheated to about $95{ }^{\circ} \mathrm{C}$ by means of a small radiation furnace and then suddeniy injected into the steady flow stream by means of a pneumatic actuator. Heat transfer then occurs by virtue of the temperature difference between the preheated cylinder and the ambient-temperature flow stream.

The time-varying voltage signal from each of the thin film gauges was supplied to a wide-bandwidth low-noise analog circuit based on the published design of 0ldfield (ref. 11). The analog output signals are directly proportional to the time-varying surface heat flux associated with each gauge.

The pre-injection temperature of the ceramic cylinder was monitored by means of two thermocouples, one located $0.25 \mathrm{~mm}$ below the stagnation thin-film gauge and the other on the cylinder centerline. Local preheat temperatures of each individual film could also be determined by monitoring the film voltage rise associated with insertion of the ceramic cylinder from the free stream into the furnace. These local preheat film temperatures for each gauge were used in the final data reduction. Temperature coefficients of resistance had been obtained for each gauge from a separate 011 bath calibration.

Heat transfer output signals from the analogs were recorded on a digitalmemory oscilloscope. Two types of signals were recorded. The first type, an 
example of which is shown in figure 4(a), was used for determining the "steadystate" or time-averaged heat transfer. In this figure, the initial heat transfer step, $q_{0}^{\prime \prime}$, results from the sudden injection of the heated cylinder

into the flow stream. The surface heat transfer rate then decays with increasing time as the cylinder surface temperature decreases. Heat transfer coefficients were determined from:

$$
h=\frac{q_{0}^{\prime \prime}}{\left(T_{f}-T_{\infty}\right)}
$$

where $T_{f}$ is the preheat temperature of the gauge and $q_{0}^{\prime \prime}$ is the heat flux occurring immediately upon injection. A small correction (about 1 percent) was included in evaluating $q_{0}$ in order to account for radiation losses. The second type of recorded signal, shown in figure $4(b)$, was used for determining time-resolved heat transfer effects due to wake passing. In this figure, the time axis is greatly expanded, revealing the heat transfer enhancement associated with each wake. The top trace is a single sweep and the bottom is an ensemble average of eight sweeps. For the purposes of ensemble averaging, the digital scope was triggered off a once-per-revolution signal provided by a fiber-optic pickup located in the rotor plane which responded to each passage of a single white-painted rotor pin tip.

The second instrumented stator pin developed for the experiments is shown in figure $3(\mathrm{c})$. It was used for making steady-state circumferentially local heat transfer measurements for comparison to the time-averaged results from the thin-film gauges. This stator pin was fabricated by wrapping and soldering a rectangular section of inconel foil (0.025 $\mathrm{mm}$ thickness) around two copper rings, which acted as electrical busses to which lead wires were attached. The inconel foll had nine thermocouples spot-welded to its inside surface at $20^{\circ}$ intervals. The entire core of the cylinder was filled with urethane foam to minimize conduction losses. The inconel foll was heated uniformiy by passing on electrical current directly through it. Local heat transfer coefficients were then inferred from the local surface temperature distribution.

Inconel is an excellent choice for this type of application due to its high electrical resistivity and low temperature coefficient of resistivity. Temperature-sensing errors due to the voltage-tap effect associated with direct electrical contact between the inconel foll and the thermocouple beads were overcome by taking two sets of measurements for each experimental condition. The polarity of the voltage across the inconel foll was reversed between the two sets of measurements. The results were then averaged, eliminating any extraneous voltages. In evaluating heat transfer coefficients, a small correction (approximately 0.75 percent) was included to account for estimated conduction and radiation losses.

With the exception of the heat transfer analog output signals, all relevant temperatures, pressures, and voltages were read and recorded by the laboratory Escort II (ref. 13) digital data acquisition system which also provided updates of any desired parameters in engineering units approximately every 2 sec for nearly continuous monitoring of experimental conditions. 


\section{RESULTS}

In order to establish a baseline for determining the relative effect of wake passage, circumferential Nusselt number distributions were first obtained with the disturbance-generator rotor removed. Freestream turbulence intensities for this configuration had been measured using a hot wire anemometer and found to lie in a range from 0.9 to 1.2 percent, depending on Reynolds number. These distributions are shown in figure 5 as a function of angular distance from the flow stagnation line. Measurements were obtained from both the inconel-foil uniform heat flux cylinder and the ceramic thin-film gauge cylinder. In addition, data obtained previously in the same rig using the $25.4 \mathrm{~mm}$ o.d. segmented-copper-strip, uniform wall-temperature cylinder were available. These data had already been shown (ref. 5) to agree closely with the results of previous investigators (refs. 15 to 17) for similar turbulence levels and Reynolds numbers.

Data from all three test cylinders are plotted in figure 5 at three representative Reynolds numbers. In the figure, a solid curve has been drawn through the data points obtained from the inconel-foil cylinder and a dashed curve through the data points obtained from the segmented-copper-strip cylinder. The figure indicates the excellent level of agreement between the data obtained by these three very different measurement techniques. Focusing on the flow-angle range from $0^{\circ}$ to $60^{\circ}$, all the data points for a specified Reynolds number fall within 10 percent of one another. At an angular distance of $80^{\circ}$, however, the Nusselt numbers measured with the inconel-foil cylinder are significantly higher than those obtained from the copper-strip cylinder. This result is in agreement with previous studies and is due to the different thermal boundary conditions presented to the flow by the two cylinders. Papell (ref. 14) has indicated that uniform heat flux and uniform wall-temperature boundary conditions yield no significant difference in Nusselt numbers for a cylinder in crossflow up to a flow angle of $60^{\circ}$. In the laminar flow separation region at an $80^{\circ}$ angular distance, however, Papell reports uniform heat flux Nusselt numbers 50 percent higher than under unfform wall-temperature conditions, which is in the same range as the present study.

It should be emphasized, that this study is the first in which a direct comparison has been made between the results of the short-duration thin film gauge technique and conventional steady-state heat transfer measurements. This direct comparison in a steady-flow tunnel was made possible by the deve1opment of the preheating and sudden injection procedure described earlier. The excellent level of agreement between the results of the short-duration technique and the steady-state techniques is reassuring and encourage further exploitation of the transient technique in steady flow tunnels.

Steady-state heat transfer results downstream of the rotating wake generator are shown in figures 6(a) and (b) for four Reynolds numbers and a Strouhal number, $S$, of 0.625 . In the figures, the circumferential Nusselt number dependence is shown for angular distances from stagnation ranging from $-80^{\circ}$ to $+80^{\circ}$. The negative angles represent points on the upwind side of the cylinders with respect to the rotation direction of the wake generator. The Nusselt numbers for these upwind points are generally slightly higher than their counterparts on the downwind side of the cylinder, owing to the asymmetry induced by the motion of the wake generator. 
The level of agreement between the three measurement techniques indicated in figure 6 is comparable to that observed in figure 5 with no rotor. The divergence of the uniform heat flux and the uniform wall temperature data points at angular distances of $\pm 80^{\circ}$ is again evident in figure 6 .

A comparison between the data of figure 6 and the data of figure 5 at a specified Reynolds number indicates the level of time-averaged heat transfer enhancement associated with wake passage. This enhancement level is summarized in figure 7, in which the ratio of stagnation-line Nusse it numbers with and without wakes, ( $\left.\mathrm{Nu} / \mathrm{Nu}_{\mathrm{S}=0}\right)$, is plotted versus Strouhal number for four different Reynolds numbers. Data obtained from the inconel-foil cylinder were used in compiling this figure since these data had exhibited the least amount of scatter. The figure indicates a somewhat surprising insensitivity of wake-induced enhancement to both Reynolds number and Strouhal number, with an average enhancement level at the stagnation line of 11 percent for this value of free-stream turbulence. For a given Reynolds number, the insensitivity of the $\mathrm{Nu} / \mathrm{Nu}_{\mathrm{S}=0}$ ratio to Strouhal number can be rationalized by the following argument. Each wake passage event causes a significant increase in timeresolved heat transfer rate with a peak typically 30 to 40 percent above the inter-wake value, as seen in figure $4(b)$. The effect of increased rotor speed is a narrowing of each wake-induced heat transfer spike, but with correspondingly more spikes. The net result, therefore, is that a change in rotation rate results in very little change in time-averaged heat transfer. For the highest Strouhal numbers studied ( $S=1.25$ in $\mathrm{fig} .7)$, however, there does appear to be a higher level of average heat transfer enhancement (about 15 percent). It is believed that at this strouhal number, wake interactions are responsible for the increased average enhancement level.

The time-averaged enhancement levels indicated in figure 7 can be directly related to the time-resolved heat transfer results from the thin film gauges. This type of comparison is shown in figure 8 for two cases. The time-resolved results shown in the figure are ensemble averages of eight sweeps. Referring to figure 8 , the average enhancement level can be calculated graphically by forming a time-weighted ratio of the area under the curve representing the periodic heat transfer signal, $A_{1}$, to the area $A_{2}$, which represents the inter-wake heat transfer. The inter-wake heat transfer level is the same as the heat transfer level obtained with no wakes (i.e. With the rotor removed). The ratio obtained in this way directly represents the heat transfer enhancement due to wake passage and can be compared to the data displayed in figure 7. The agreement between the enhancement levels obtained from the steady-state measurements and the time-resolved measurements is remarkable and clearly reveals the relationship between wake passing and heat transfer.

With regard to the effect of wake passage on heat transfer enhancement (over the no-rotor case) at circumferential locations other than along the stagnation line, table I summarizes enhancement effects at angular distances from $-80^{\circ}$ to $+80^{\circ}$ for a representative Reynolds number of 76000 . The incone $1-$ foll cylinder was again used for this comparison. For angular distances from $-40^{\circ}$ to $+40^{\circ}$, the trends associated with the stagnation line data apply, with enhancement levels of approximately 11 percent and very little dependence on strouhal number. As observed previously, slightiy higher enhancement is associated with $S=1.25$. For angular distances of $\pm 60^{\circ}$ and $\pm 80^{\circ}$, significantly higher enhancement is observed. In particular, at $-80^{\circ}$, enhancement levels range from 28 to 45 percent, with a relatively strong dependence on Strouhal 
number. These strong effects are indicative of the sensitivity of the boundary layer at these near-separation points to the wake disturbances.

As a final comment on the time-resolved heat transfer results, it is interesting to compare the output signals from two adjacent gauges on an expanded time scale. For example, figure 9 shows heat transfer signals from gauges located at $0^{\circ}$ and $+20^{\circ}$ from the stagnation line. These signals resulted from the same single wake passage event and are unaveraged. The degree of unsteadiness within an individual wake is demonstrated in the figure (and in fig. $4(b)$ as well). Even more interesting is the obvious correlation between the two signals, indicating the probable relationship of the unsteady heat transfer excursions to coherent structures existing in the wake.

\section{CONCLUSIONS}

A heat transfer measurement technique involving the preheating and sudden injection into a flow of a ceramic cylinder instrumented with platinum thin film heat flux gauges has been developed. The results of this transient technique were compared to results obtained from two instrumented steady-state cylinders for the local heat transfer distribution around a cylinder in crossflow. Comparisons were made for cases in which the cylinders were situated in a steady flow and also for several cases in which the cylinders were exposed to the unsteady flow produced by an upstream rotating spoked-wheel wake generator. The results of the comparisons were quite favorable, encouraging further exploitation of the thin-film gauge heat transfer technique for timeresolved measurements in steady flow tunnels.

Time-averaged wake-induced stagnation heat transfer enhancement levels above the no-wake case ( 1 percent freestream turbulence) were found to be about 10 percent for the four cylinder Reynolds numbers (ranging from 36000 to 96 000) included in the study. This enhancement level was nearly independent of bar-passing frequency and was related directly to the time integral of the heat transfer spikes observed at the bar passing frequency. These wake-induced time-resolved heat transfer spikes were observed to have peak magnitudes averaging 30 to 40 percent above the inter-wake heat transfer level.

Inspection of time-resolved heat transfer signals from adjacent gauges revealed a strong correlation between the unsteady heat transfer excursions experienced at each gauge during a single wake-passing event. This correlation is indicative of the probable relationship of the unsteady heat transfer excursions to coherent structures existing in the wake. Future work will focus on quantifying this correlation and relating it to flow structures.

\section{REFERENCES}

1. Doorly, D.J.; and 0ldfield, M.L.G.: Simulation of the Effects of Shock Wave Passing on a Turbine Rotor Blade. J. Eng. Gas Turbines Power, vol. 107, no. 4, 0ct. 1985, pp. 998-1006. 
2. Ashworth, D.A., et a1.: Unsteady Aerodynamic and Heat Transfer Processes in a Transonic Turbine Stage. J. Eng. Gas Turbines Power, vol. 107, no. 4 , Oct. 1985, pp. 1022-1030.

3. Dunn, M.G., et al.: Time-Resolved Heat Flux Measurements for the Rotor of a Full-Stage Turbine: Description of Analysis Technique and Typical Data. Submitted for presentation at the ASME Gas Turbine Conference, Dusseldorf, West Germany, June 1986.

4. Simoneau, R.J., et al.: Effect of a Rotor Wake on Heat Transfer from a Circular Cylinder. NASA TM-836133, 1984.

5. Morehouse, K.A.; and Simoneau, R.J.: "Effect of a Rotor Wake on the Local Heat Transfer on the Forward Half of a Circular Cylinder. Submitted for presentation at the Eighth International Heat Transfer Conference, San Francisco, Aug. 1986.

6. Doorly, D.J.: A Study of the Effect of Wake-Passing on Turbine Blades, OUEL-1515/84, Engineering Lab, Oxford University, England, 1983.

7. Vida1, R.J.: Model Instrumentation Techniques for Heat Transfer and Force Measurements in a Hypersonic Shock Tunne1. Report No. AD-917-A-1, Corne11 Aeronautical Laboratory, Feb. 1956.

8. Ligrani, P.M.; Camci, C.; and Grady, M.S.: Thin Film Heat Transfer Gage Construction and Measurement Details. VKI-TM-33, VonKarman Institute for Fluid Dynamics, Rhode-St-Genese, Belgium, Dec. 1982.

9. Schultz, D.L.; and Jones, T.V.: Heat Transfer Measurements in Short Duration Hypersonic Facilities. AGARD AG-165, AGARD, Paris, France, 1973.

10. Schultz, D.L., et al.: Measurement of the Heat Transfer Rate to Turbine Blades and Nozzle Guide Vanes in a Transient Cascade. International Heat Transfer Conference, 6th, Vo1. 2, Hemisphere Publishing, Washington, D.C., 1978, pp. 73-78.

11. Oldfield, M.L.G.; Burd, H.J.; and Doe, M.G.: Design of Wide-Bandwidth Ana logue Circuits for Heat Transfer Instrumentation in Transient Tunnels. Heat and Mass Transfer in Rotating Machinery, D.E. Metzger and N.H. Afgan, eds., Hemisphere Publishing, Washington, D.C., 1984, pp. 233-258.

12. Skinner, G.T.: Analog Network to Convent Surface Temperature to Heat Flux. CAL-100, Cornell Aeronautical Laboratory, Buffalo, NY, Feb. 1960.

13. Miller, R.L.: Escort: A Data Acquisition and Display System to Support Research Testing. Electro/78 Conference Record, IEEE, 1978, Paper 14/3.

14. Papel1, S.S.: Influence of Thermal Boundary Conditions on Heat Transfer from a Cylinder in Crossflow. NASA TP-1894, 1981.

15. Kestin, J; and Wood, R.T.: The Influence of Turbulence on Mass Transfer from Cylinders. J. Heat Trans., vol. 93, no. 4, Nov. 1971, pp. 321-327. 
16. Vanfossen, G.J., Jr.; and Simoneau, R.J.: "Preliminary Results of a Study of the Relationship Between Free Stream Turbulence and Stagnation Region Heat Transfer," ASME Paper 85-GT-84, Mar. 1985.

17. Giedt, W.H.: Effect of Turbulence Level of Incident Air Stream on Local Heat Transfer and Skin Friction on a Cylinder. J. Aeronaut. Sci., vol. 18, no. 11, Nov. 1951, pp. 725-730. 
TABLE I. - HEAT TRANSFER ENHANCEMENT DUE TO WAKE PASSAGE DEPENDENCE ON CIRCUMFERENTIAL POSITION AND WAKE

PASSING FREQUENCY, $\mathrm{Re}=76000$

\begin{tabular}{|c|c|c|c|c|}
\hline \multirow{2}{*}{$\begin{array}{l}\text { Angle from } \\
\text { stagnation }\end{array}$} & \multicolumn{4}{|c|}{ Nu/NuS=0 } \\
\cline { 2 - 5 } & $S=0.189$ & $S=0.311$ & $S=0.625$ & $S=1.25$ \\
\hline-80 & 1.285 & 1.313 & 1.363 & 1.450 \\
-60 & 1.139 & 1.151 & 1.168 & 1.208 \\
-40 & 1.108 & 1.116 & 1.115 & 1.144 \\
-20 & 1.101 & 1.106 & 1.106 & 1.121 \\
0 & 1.120 & 1.111 & 1.112 & 1.132 \\
20 & 1.095 & 1.104 & 1.099 & 1.119 \\
40 & 1.106 & 1.111 & 1.111 & 1.131 \\
60 & 1.131 & 1.139 & 1.148 & 1.190 \\
80 & 1.183 & 1.218 & 1.238 & 1.321 \\
\hline
\end{tabular}




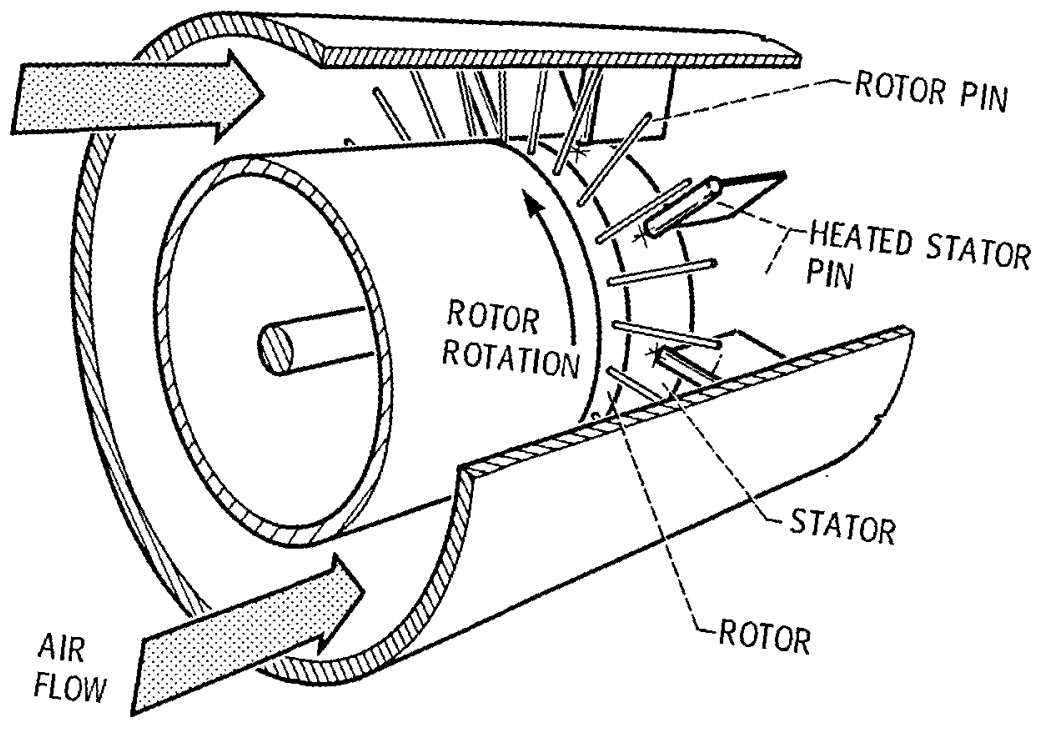

Figure 1. - Concept of rotor wake heat transfer experiment. 


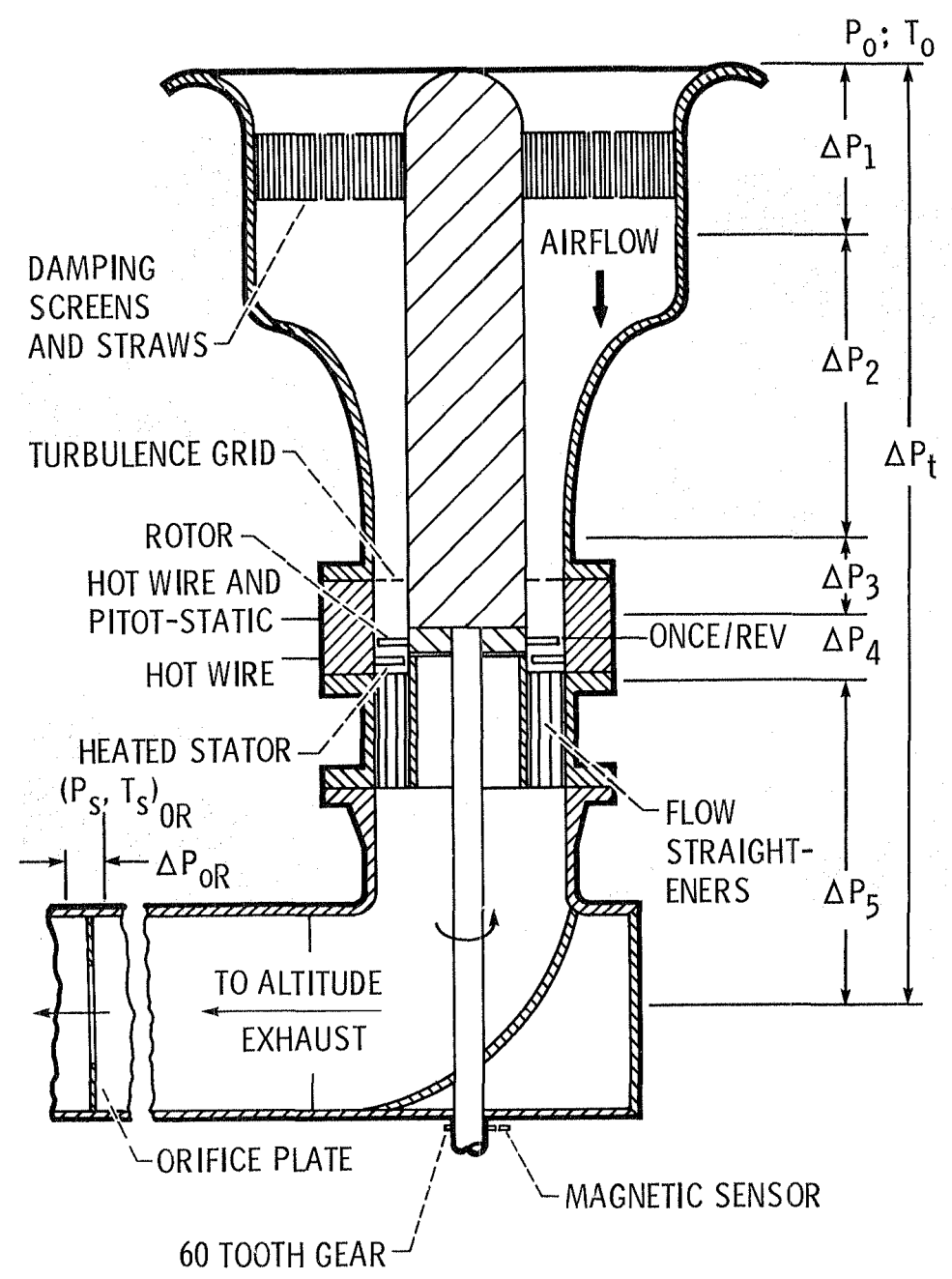

Figure 2. - Rotor wake rig flow schematic. 


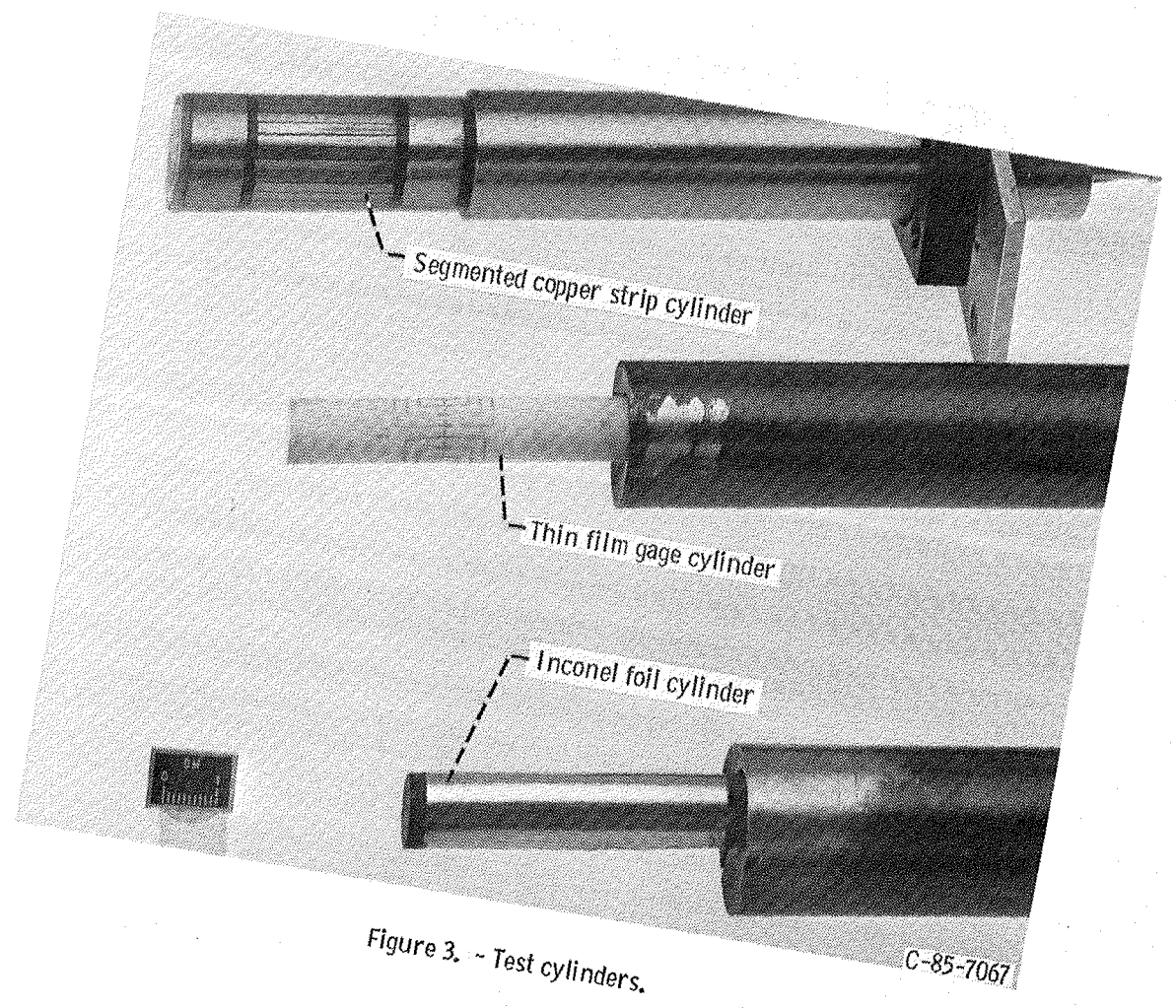




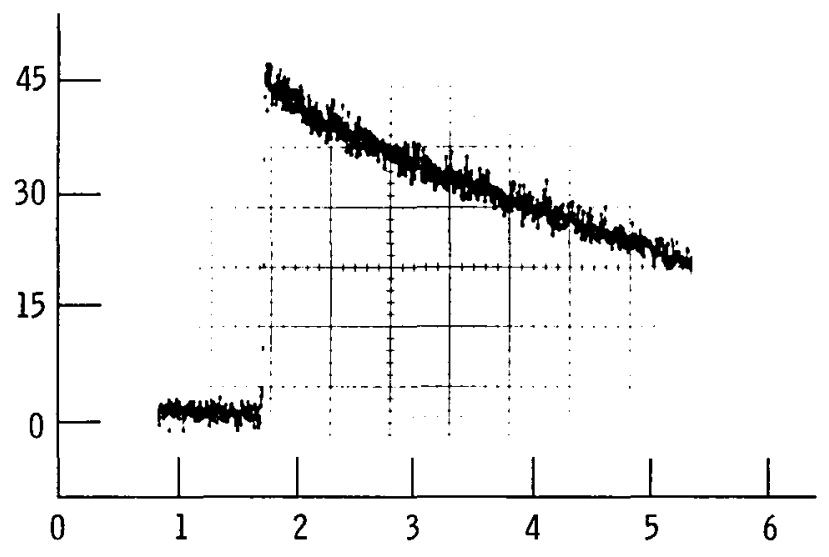

(a) "Steady-state"; $R e=76000 ; S=0.725$.

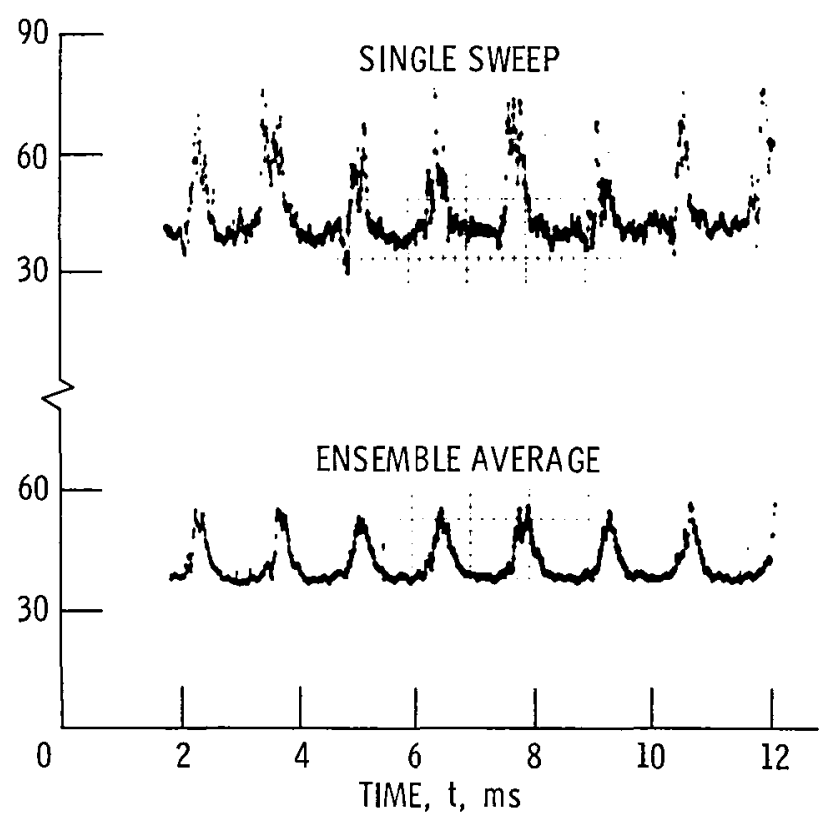

(b) Time-resolved; $R e=76$ 000; $S=0.616$.

Figure 4. - Stagnation line heat transfer analog output signals. 


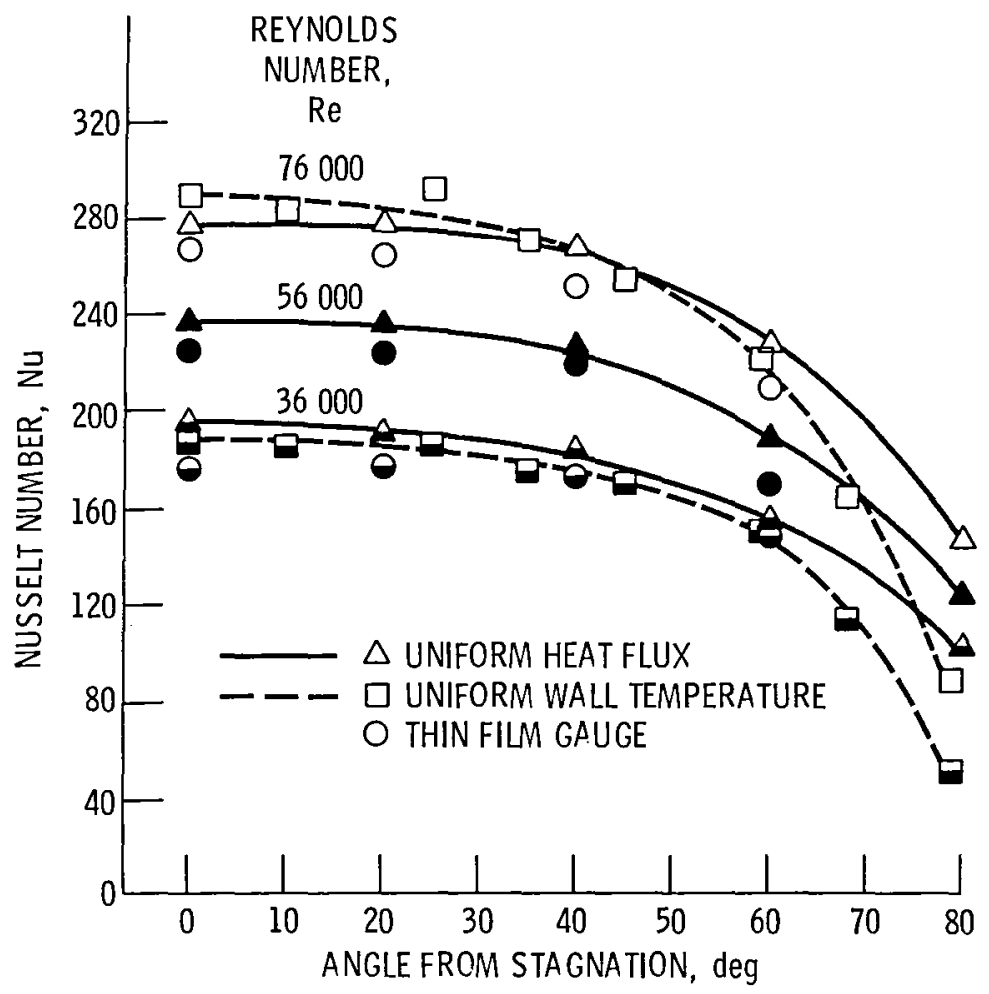

Figure 5. - Steady state circumferential Nusselt number distributions with rotor removed. 


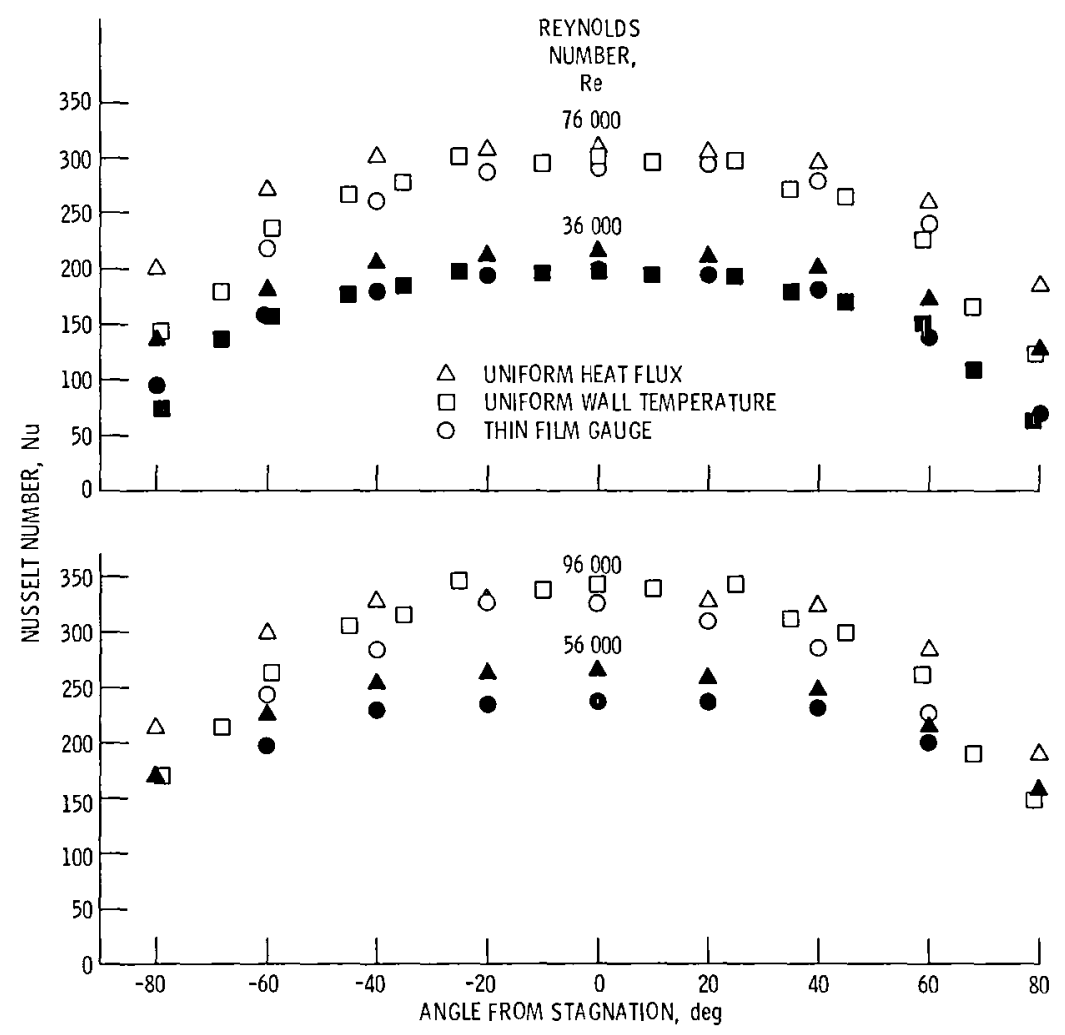

Figure 6. - Steady state circumferential Nusselt number distributions with rotor $(S=0.625)$.

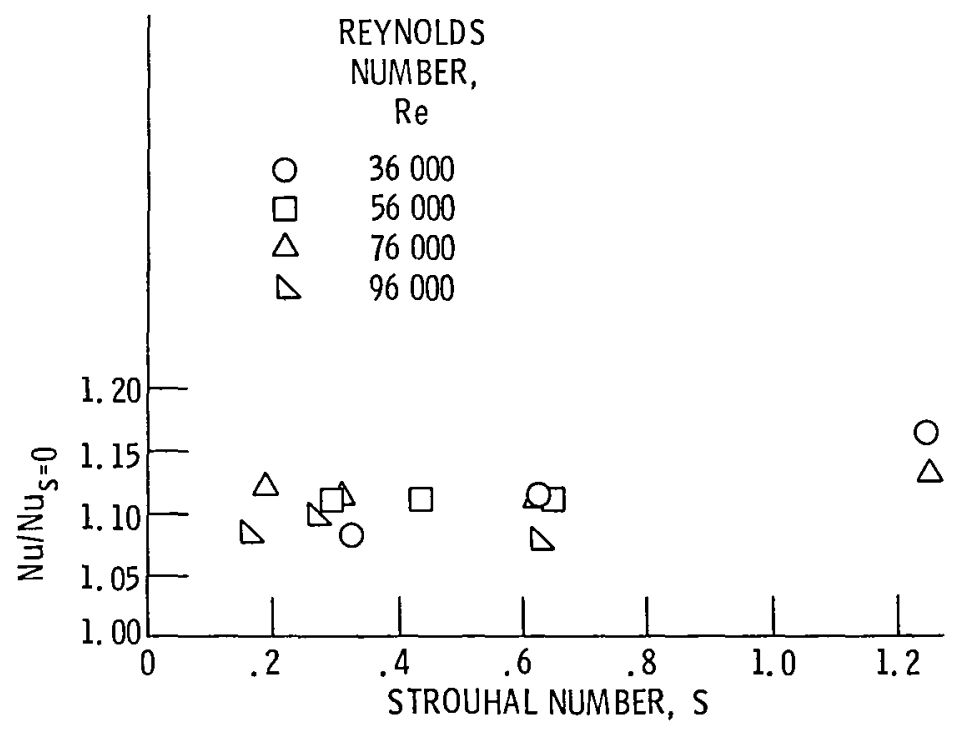

Figure 7. - Stagnation line heat transfer enhancement due to wake passage. 

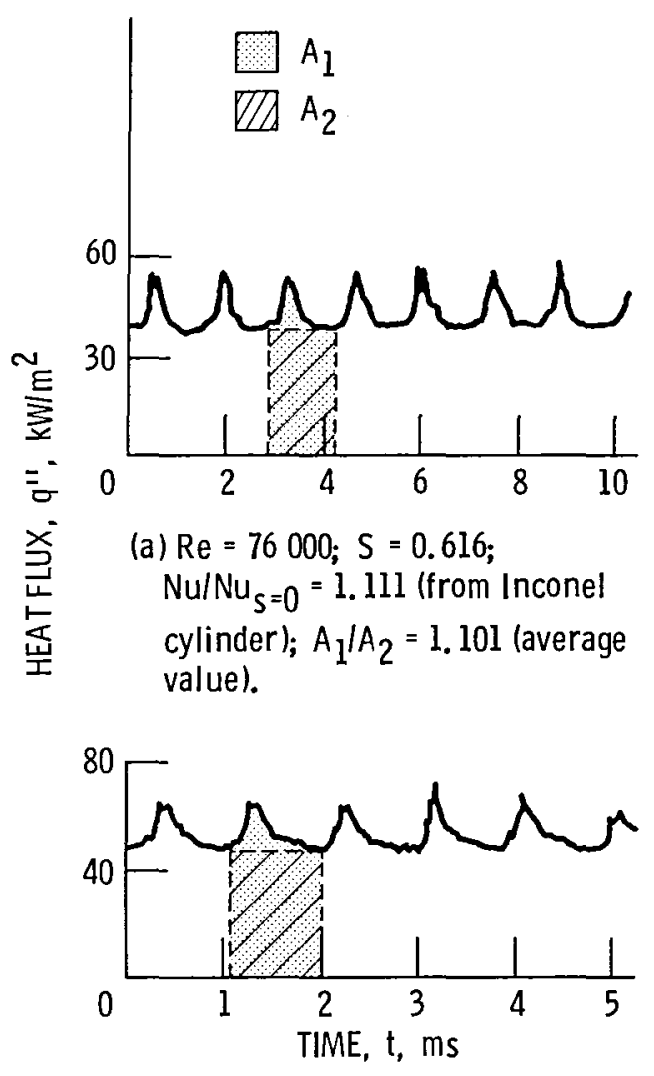

(b) $R e=96000 ; S=0.724$;

$\mathrm{Nu} / \mathrm{Nu}_{\mathrm{s}}=0=1.078$ (from Inconel cylinder); $A_{1} / A_{2}=1.081$ (average value).

Figure 8. - Comparison between wakeinduced enhancement levels from steady-state and time-resolved measurements at cylinder stagnation line. 


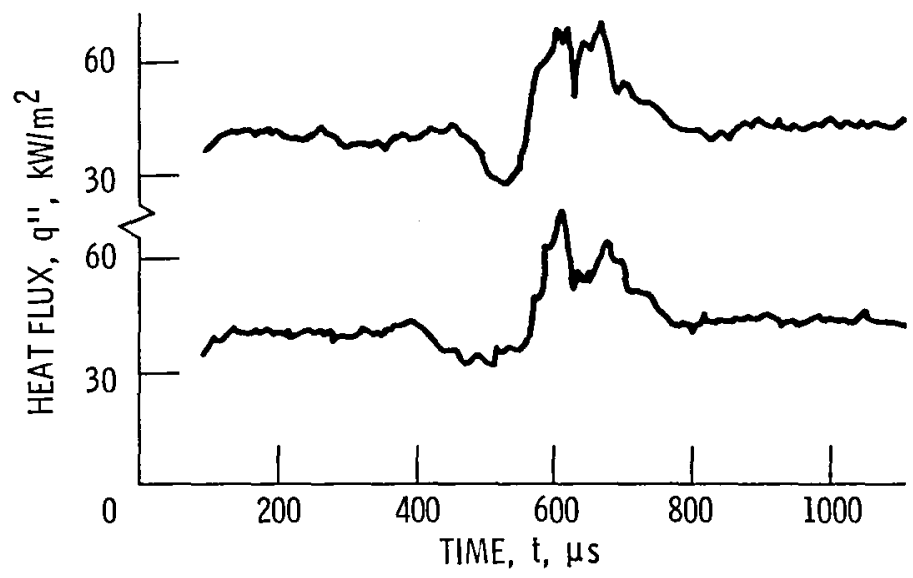

Figure 9. - Time-resolved heat transfer from adjacent guages. 


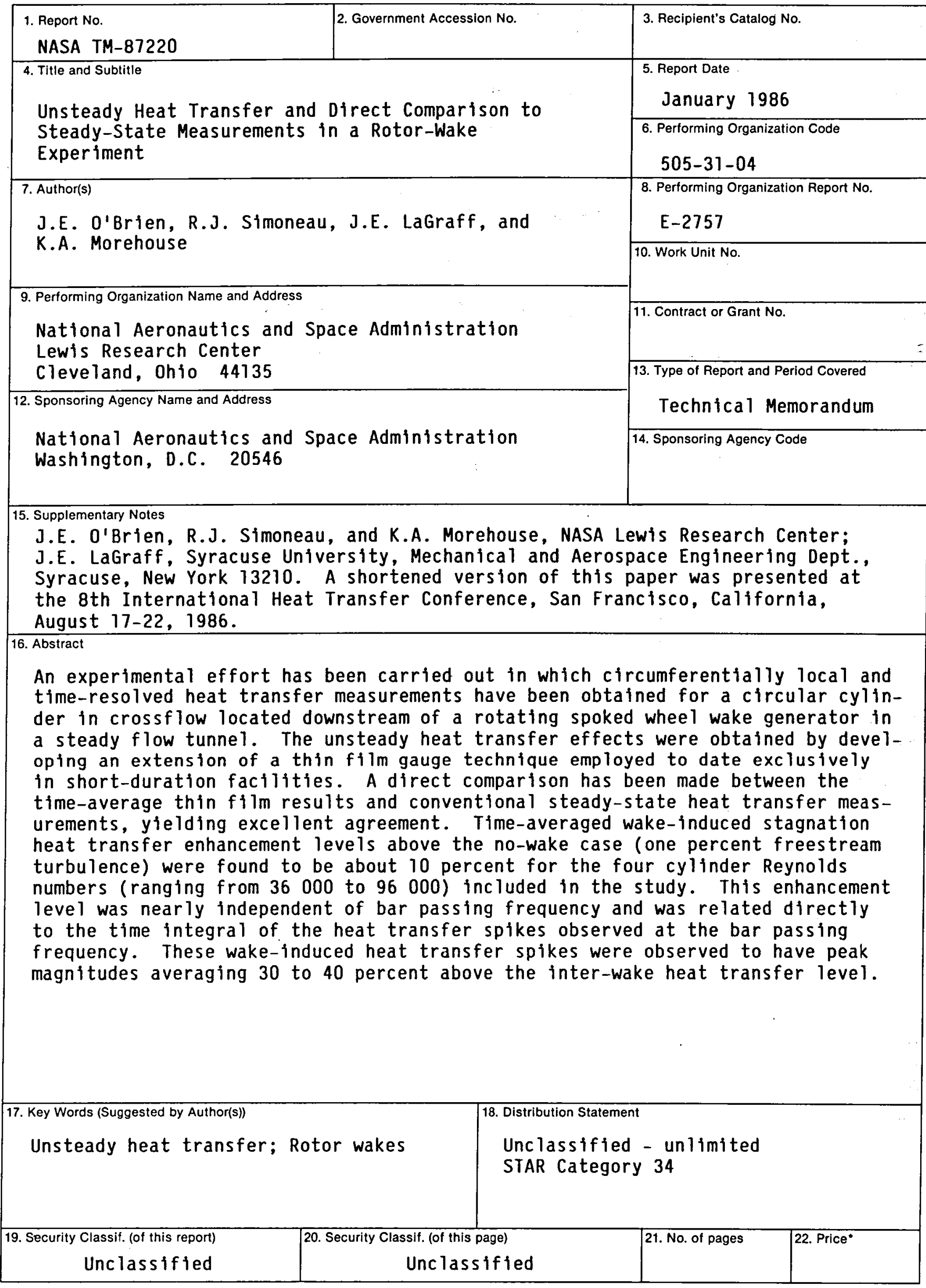

*For sale by the National Technical Information Service. Springfield, Virginia 22161 
End of Document 